\title{
Pharmacoeconomic Analysis and Treatment Pattern in Sepsis Patients: A Cross-sectional Prospective and Retrospective Study
}

\author{
Maneesha Erraboina', Karthik Gopagoni' ${ }^{1}$, Abhilash Manthen', Sangram Vurumadla², \\ Suresh Bandari ${ }^{3, *}$
}

1'Department of Pharmacy Practice, Rohini Superspeciality Hospitals and St. Peter's Institute of Pharmaceutical Sciences, Hanamkonda, Warangal, Telangana, INDIA.

2Department of Pharmacy Practice, St. Peter's Institute of Pharmaceutical Sciences, Hanamkonda, Warangal, Telangana, INDIA.

${ }^{3}$ Department of Pharmaceutics, St. Peter's Institute of Pharmaceutical Sciences, Hanamkonda, Warangal, Telangana, INDIA.

\begin{abstract}
Objectives: Increasing health care cost is a major concern in the developing world and has increased the economic burden for a common man. Pharmacoeconomics refers to the scientific discipline that compares the value of one pharmaceutical drug or drug therapy to another. The study objective is to describe and appraise the pattern of antibiotics prescribing based on the blood culture report and to evaluate the cost analysis in sepsis patients. Methods: A retrospective and prospective analysis was conducted at tertiary care hospitals, Warangal. The follow up was done for all patients enrolled in the study. Antibiotic-prescription pattern in both blood culture positive and negative were analyzed and compared. The data collection comprises the direct medical and non-medical cost, cost of medications prescribed during the therapy and while discharge. Results: A combined analysis of antibiotic pattern and cost of treatment was performed. The most commonly prescribed antibiotics were Piperacillin + Tazobactum, Vancomycin, Clindamycin, Tobramycin, Cefpodoxime, Meropenem and Imipenam. The cost for blood culture positive patients was $35,920 \pm 15,292$ rupees and blood culture negative patients was $18,082 \pm 7,987$ rupees. The blood culture and sensitivity testing was carried out and the common organisms isolated were Escherichia coli and Klebsiella pneumoniae. The overall cost of Klebsiella pneumoniae patients (Rs.35,688 $\pm 15,162$ ) was higher than the Escherichia coli (Rs.24,767 $\pm 15,498$ ). The dissimilarity in the cost of therapy may be due to change of treatment site. Conclusion: The present study infers that treatment pattern of antibiotics varied based on the blood culture report of an individual patient; for majority cohort piperacillin + tazobactum was the drug of choice for both blood culture positive and negative sepsis patients. On the basis of current cost analysis data, the treatment cost of blood culture positive patients is significantly high than that of blood culture negative patients.
\end{abstract}

Key words: Sepsis, Pharmacoeconomic analysis, Treatment pattern, Antibiotics, Direct medical cost, Direct non-medical cost.

\section{INTRODUCTION}

Sepsis is defined as the presence or presumed presence of an infection accompanied by systemic manifestations of an inflammatory response. When severe, organ dysfunction is usually noted, with or without the presence of refractory hypotension. The most common primary sources of infection resulting in sepsis are the lungs, the abdomen and the urinary tract. Typically, 50\% of all sepsis cases start as an infection in the lungs. ${ }^{1,2}$

Sepsis causes millions of deaths globally each year and is the most common cause of death in people who have been hospitalized. The worldwideincidence of sepsisis estimated to be
DOI: 10.5530/ijopp.12.2.20

Address for correspondence: Dr. Suresh Bandari, (M.Pharm, Ph.D), Department of Pharmaceutics, St. Peter's Institute of Pharmaceutical sciences, Hanamkonda, Warangal- 506 00I, Telangana, INDIA.

Phone no: +91-9849557616

Email: reachbandari@gmail.com

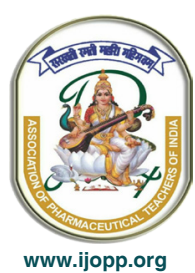


18 million cases per year. A study by the Agency for Healthcare Research and Quality (AHRQ) of selected states found that there were approximately 651 hospital stays per 100,000 populations with a sepsis diagnosis in 2010. It is the second-leading cause of death in non-coronary Intensive Care Unit (ICU) patients and the tenth-most-common cause of death overall. ${ }^{3}$ Fatality rates of the sepsis syndrome range from 23 to $46 \%$, varying based on the phase of the continum being evaluated..$^{4-6}$ Approximately 751000 new cases of severe sepsis are diagnosed each year with about 500 deaths daily across the United States of America [USA] $\cdot{ }^{5-7}$ Prolonged Length of Stay (LOS) is common, with the average patient requiring hospitalization for 19.6 days. A similar disease burden has been reported in Europe and Australia with cumulative annual incidences ranging from 51 to 206 cases per 100000 populations. ${ }^{8,9}$ In the USA, approximately $61 \%$ of all patients ultimately diagnosed with sepsis initially present to an Emergency Department (ED), with an annual estimated associated cost of US $\$ 16.7$ billion. ${ }^{10}$ While no national figures are available for India, anecdotal reports from the Intensive Care Unit (ICU) of various hospitals, suggest that sepsis accounts for a significant proportion of deaths among their admitted patient population. One of the major contributing factors for emergence of resistance and treatment failure due to irrational use of antibiotics is irrational prescribing with respect to dose, frequency and duration of antibiotics, not considering compatibility and drug interaction effect of co-administered drug. ${ }^{11}$

Although much of the care of severe sepsis occurs in the intensive care unit, the majority of hospital cases of sepsis originate in the Emergency Department (ED) with an average ED length of stay of almost $5 \mathrm{hrs} .{ }^{12}$ The management of septic patients by ED physicians in the "golden hour" thus plays a pivotal role in their clinical outcome. ${ }^{13}$ This was clearly demonstrated by Rivers and colleagues, in their landmark evaluation of Early Goal Directed Therapy (EGDT) for severe sepsis. By aggressively responding to temporal changes in cardiac preload, after load and contractility and oxygen delivery/ demand, these investigators were able to decrease absolute mortality by $16 \%$ and LOS by 3.8 days per patient. ${ }^{14}$ Since its original publication, several observational studies have supported the use of EGDT in the ED as a method of improving mortality in severe sepsis. ${ }^{4-6}$ Furthermore, the international Surviving Sepsis Campaign (SSC) guidelines recommend the use of EGDT in the earliest phases of the patient's clinical course. ${ }^{7}$ Unfortunately, the interventions comprising EGDT have documented barriers to adoption including inadequate staffing and equipment and lack of education, training and procedural competency. ${ }^{89}$ These barriers may also relate to costs, value and resource use and thus evaluating these aspects of EGDT are important before widespread implementation. From an intuitive standpoint, offering more aggressive, time intensive and resource intensive care would result in higher costs of delivery. However, given the findings of improvement in outcomes, examining both the costs and health consequences of EGDT (i.e., cost effectiveness) is important and of high priority. Thus, the aim of our study was to assess the cost-effectiveness of implementing EGDT as a routine protocol in the ED care of severe sepsis. Specific objectives of this study were also to evaluate the incidence and outcomes of severe sepsis and septic shock and also to ascertain information regarding relative practice antibiotic treatment patterns for sepsis management in a representative, resource-limited medical centre.

\section{MATERIAL AND METHODS \\ Duration and design of study}

This was a retrospective and prospective observational study of patients with severe sepsis and septic shock who presented at emergency division of various hospital sites in Warangal district, Telangana for a period of 10 months. The study procedure is shown in Figure 1. All the patients visiting these multiple sites were reviewed on daily basis with blood culture test report (positive and negative), with SIRS (Systemic Inflammatory Response Syndrome), adequate organ function and without history of allergies. Patients who met two or more systemic inflammatory response syndrome (SIRS) criteria [i.e. Heart Rate (HR) > 90 beats $/ \mathrm{min}$, temperature $>38^{\circ} \mathrm{C}$ or $<36^{\circ} \mathrm{C}$, respiratory rate $(\mathrm{RR})>20$ breaths/min, White Blood Cell (WBC) count $>12000$ or $<4000$ or $>10 \%$ bands and baseline whole blood lactate concentration $\geq 4 \mathrm{mmol} / \mathrm{L}]$ and were diagnosed with sepsis, were eligible for study inclusion. Those with concurrent acute illness (i.e. cerebrovascular event, coronary syndrome, cardiogenic pulmonary edema, status asthmaticus, primary dysrhythmia, seizure, drug overdose or major trauma) which necessitated disease specific intervention and those with active cancer, on immunosuppressant or active 'do not resuscitate' orders were excluded.

Data were prospectively collected from eligible patients ("cases") between December 2015 and August 2016 using standardized data collection forms. Baseline characteristics, demographics, co-morbid conditions, vital signs, site of infection and laboratory data were collected in all patients. All data elements were readily available from existing records and additional information regarding cost of the interventions was solicited. This project did not interfere with patient care and waiver 


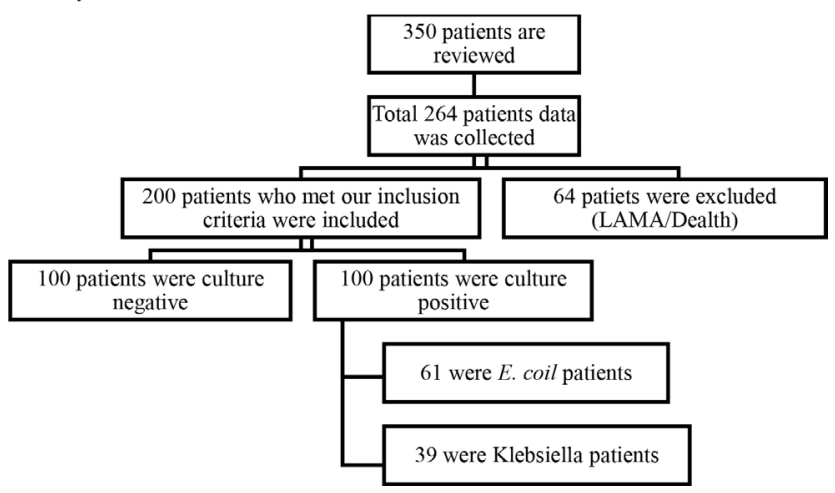

Figure 1: Study Procedure.

of informed consent was permitted by Institutional Ethics Committee of the Hospital. Descriptive clinical, demographic and historical data for cases as well as the physician management patterns of the cases were analyzed. Costs incurred for all laboratory tests were noted. Current medication and discharge medication and their respective cost were also noted. Hospital costs for each patient were taken from the hospital's cost accounting system. The cost analysis was done for the collected data and treatment pattern based on the blood culture test was analyzed (Figure 1).

\section{RESULTS}

A total of 264 patients were reviewed during the study. Among them 200 (57.1\%) patients met our study criteria which included 127 male patients $(63.5 \%)$ and 73 female patients $(36.5 \%)$. Out them 100 patients $(50 \%)$ were found blood culture positive and $100(50 \%)$ patients were found blood culture negative. Among blood culture positive patients Escherichia coli was predominant microorganism found in 61 patients $(61 \%)$ followed by Klebsiella pneumonia found in 39 patients (39\%). The average WBC count in culture positive patients was 25,789 cells per micro liter and in blood culture negative patients WBC count was 22,696 cells per micro liter. The major symptoms observed in recruited sepsis patients were fever, $(42.5 \%)$ followed by weakness $(25 \%)$, respiratory distress $(18.5 \%)$, vomiting $(8 \%)$ and cough $(6 \%)$. Above information is given in Table 1.

The distribution of patients based on their age was given in Table 2.128 patients (64\%) were neonates, 24 patients $(12 \%)$ were adults, 24 patients $(12 \%)$ were of middle age, 20 patients $(10 \%)$ were infants, 2 patients $(2 \%)$ were geriatrics, 1 patient $(0.5 \%)$ was child and 1 patient $(0.5 \%)$ was in adolescence group.

Table 3 shows the frequency and cumulative frequency, percent and cumulative percent of the patients with

\begin{tabular}{|c|c|c|c|}
\hline Gender & $\begin{array}{c}\text { Number of } \\
\text { patients (\%) }\end{array}$ & $\begin{array}{l}\text { Cumulative } \\
\text { Frequency }\end{array}$ & $\begin{array}{c}\text { Cumulative } \\
\text { Percent }\end{array}$ \\
\hline Male & $127(63.5 \%)$ & 200 & 100.00 \\
\hline Female & 73 (36.5\%) & 73 & 36.50 \\
\hline $\begin{array}{l}\text { Culture } \\
\text { Report }\end{array}$ & $\begin{array}{l}\text { Number of } \\
\text { patients }\end{array}$ & $\begin{array}{l}\text { Cumulative } \\
\text { Frequency }\end{array}$ & $\begin{array}{c}\text { Cumulative } \\
\text { Percent }\end{array}$ \\
\hline Positive & $100(50 \%)$ & 200 & 100.00 \\
\hline Negative & $100(50 \%)$ & 100 & 50.00 \\
\hline $\begin{array}{l}\text { Culture } \\
\text { Organism }\end{array}$ & $\begin{array}{c}\text { No. of } \\
\text { patients (\%) }\end{array}$ & $\begin{array}{l}\text { Cumulative } \\
\text { Frequency }\end{array}$ & $\begin{array}{c}\text { Cumulative } \\
\text { Percent }\end{array}$ \\
\hline $\begin{array}{c}\text { Escherichia } \\
\text { coli }\end{array}$ & $61(61 \%)$ & 61 & 61.00 \\
\hline $\begin{array}{c}\text { Klebsiella } \\
\text { pneumoniae }\end{array}$ & $39(39 \%)$ & 100 & 100.00 \\
\hline
\end{tabular}

Frequency Missing = 100

\section{Table 2: Age wise Distribution of Sepsis patients.}

\begin{tabular}{lccc}
\multicolumn{1}{c}{ Age group } & $\begin{array}{c}\text { Culture } \\
\text { Positive }\end{array}$ & $\begin{array}{c}\text { Culture } \\
\text { Negative }\end{array}$ & Total (\%) \\
\hline Neonates (0-30 days) & 74 & 54 & $128(64 \%)$ \\
Infants (30 days-1 yr) & 5 & 15 & $20(10 \%)$ \\
Children (1 yr-11 yrs) & - & 1 & $1(0.5 \%)$ \\
Adolescence (11 yrs-16 yrs) & - & 1 & $1(0.5 \%)$ \\
Adults (17 yrs-45 yrs) & 7 & 17 & $24(12 \%)$ \\
Middle Age (46 yrs-60 yrs) & 11 & 13 & $24(12 \%)$ \\
Geriatrics (>65 yrs) & 2 & - & $2(1 \%)$ \\
\hline
\end{tabular}

Yrs - Years

\section{Table 3: Frequency procedure.}

\begin{tabular}{ccccc}
$\begin{array}{c}\text { Culture } \\
\text { report } \\
\text { based on } \\
\text { age }\end{array}$ & Frequency & Percent & $\begin{array}{c}\text { Cumulative } \\
\text { Frequency }\end{array}$ & $\begin{array}{c}\text { Cumulative } \\
\text { Percent }\end{array}$ \\
\hline Negative & 51 & 32.69 & 51 & 32.69 \\
Positive & 105 & 67.31 & 156 & 100.00 \\
\hline
\end{tabular}

Frequency Missing $=44$

culture positive both organisms and culture negative.

Treatment pattern and total antibiotic usage for both blood culture positive and negative patients were analyzed in the study. Intravenous and oral route of piperacillin and tazobactum $33.4 \%$ in E. coli blood culture positive, $56.4 \%$ in Klebsiella blood culture positive, $33.6 \%$ in blood culture negative) and vancomycin (5.8\% in E. coli blood culture positive, $23.6 \%$ in Klebsiella blood culture positive, $14 \%$ in blood culture negative) were prescribed more frequently compared to the other antibiotic class of drugs like cefpodoxime $29.4 \%$ in $E$. coli blood culture positive, $21.9 \%$ in blood culture negative), clindamycin (15.4\% in Klebsiella blood culture positive), tobramycin Indian Journal of Pharmacy Practice, Vol 12, Issue 2, Apr-Jun, 2019 
(31.4\% in E. coli blood culture positive, $18.2 \%$ in blood culture negative), meropenem (12.3 in blood culture negative), imipenem $(4.6 \%$ in Klebsiella blood culture positive). Majority of the drugs were given by intravenous route $(40.3 \%)$ followed by oral route (tablets $-24.7 \%$, syrup - $20.2 \%$ and drops $-14.8 \%$ ). The most commonly prescribed drugs other than antibiotics were paracetamol $(40.5 \%)$, pantaprazole $(20.5 \%)$, tramadol $(11.5 \%)$, dopamine $(14.5 \%)$ and multivitamin (13\%). Most of the drugs were prescribed with generic names $(76.3 \%)$ followed by brand names $(23.7 \%)$. The patients with blood culture positive (both organism) stayed for 11days and patients with blood culture negative stayed for 8 days for treatment of sepsis.

From the obtained data, the reoccurrence rate for Klebsiella was greater $(42.2 \%)$ than $E$. coli which accounted for $35.1 \%$ and for blood culture negative patient's recurrence was found to be $24 \%$ which is less than in blood culture positive patients was shown in Table 4.

Table 5 shows the statistics, $t$-tests and equality of variances on cost of the patients based on the reoccurrence.

\section{Table 4: Reoccurrence based on culture report.}

\begin{tabular}{ccc} 
Culture Report & Reoccurrence (\%) & $\begin{array}{c}\text { No Reoccurrence } \\
(\%)\end{array}$ \\
\hline E. coli & $21(35.1 \%)$ & $40(64.9 \%)$ \\
Klebsiella & $17(42.2 \%)$ & $22(57.8 \%)$ \\
Negative & $24(24 \%)$ & $76(76 \%)$ \\
\hline
\end{tabular}

In this study cost analysis of sepsis patients were done by two ways, based on type of organism involved in the infection and hospital stay. Table 6 shows the information about the average cost for hospital stay based on number of days, the number of days and cost of hospital stay were increasing significantly.

Table 7 shows the statistics, t-tests and equality of variances on cost of the patients based on gender.

Table 8 shows information about average cost for hospital stay based on culture report. The pharmacoeconomic aspects of the patients the cost of treatment in blood culture positive patients was Rs.35,920 $\pm 15,292$, the cost for patients with presence of Klebsiella was Rs.35, $688 \pm 15,162$, the cost for patients with presence of E. coli was Rs. 24,767 $\pm 15,498$ and the cost of treatment in blood culture negative patients was Rs. 18,082 \pm 7,987.

Table 9 shows the statistics, $t$-tests and equality of variances on cost of the patients based on blood culture report.

Table 10 shows the statistics, $t$-tests and equality of variances on cost of the patients based on culture organism.

\begin{tabular}{cc}
\hline Table 6: Cost Analysis based on hospital stay. \\
\hline Hospital stay (days) & Cost (Rs.) \\
\hline $0-5$ days & Rs. 15,602 \\
$6-10$ days & Rs. 28,275 \\
$11-15$ days & Rs. 42,960 \\
$16-20$ days & Rs. 50,699 \\
\hline
\end{tabular}

Table 5: Statistics based on the reoccurrence rate.

\begin{tabular}{|c|c|c|c|c|c|c|c|c|c|c|c|}
\hline \multicolumn{12}{|c|}{ Statistics } \\
\hline Variable & Reoccurrence & $\mathbf{N}$ & $\begin{array}{c}\text { Lower } \\
\text { CL } \\
\text { Mean }\end{array}$ & Mean & $\begin{array}{c}\text { Upper } \\
\text { CL } \\
\text { Mean }\end{array}$ & $\begin{array}{l}\text { Lower } \\
\text { CL Std } \\
\text { Dev }\end{array}$ & Std Dev & $\begin{array}{c}\text { Upper } \\
\text { CL Std } \\
\text { Dev }\end{array}$ & $\begin{array}{l}\text { Std } \\
\text { Err }\end{array}$ & Minimum & Maximum \\
\hline Cost & NR & 138 & 27648 & 29747 & 31846 & 11150 & 12468 & 14141 & 1061.3 & 8810 & 69800 \\
\hline Cost & $\mathrm{R}$ & 62 & 33937 & 37018 & 40100 & 10311 & 12134 & 14746 & 1541 & 22498 & 74150 \\
\hline Cost & Diff (1-2) & & -6289 & -7271 & -8254 & 839 & 334 & -605 & -479.7 & & \\
\hline
\end{tabular}

N-Number of patients; CL - Confidence level; Std Dev - Standard Deviation; Std Err - Standard Error.

\begin{tabular}{|c|c|c|c|c|c|}
\hline \multicolumn{6}{|c|}{$T$-Tests } \\
\hline Variable & Method & Variances & DF & $t$ Value & $\operatorname{Pr}>|t|$ \\
\hline Cost & Pooled & Equal & 198 & -3.85 & 0.0002 \\
\hline Cost & Satterthwaite & Unequal & 156 & -3.89 & 0.0002 \\
\hline
\end{tabular}

DF - Degree of Freedom; Pr-Probability.

\begin{tabular}{cccccc}
\hline & \multicolumn{4}{c}{ Equality of Variances } \\
\hline Variable & Method & Num DF & Den DF & Pr Value & \\
\hline Cost & Folded F & 137 & 61 & 1.06 & 0.8259 \\
\hline
\end{tabular}

Num DF- Numerator of degrees of freedom; Den DF - Denominator of degree of freedom; Pr - Probabality. 
Table 7: Statistics based on the gender.

\begin{tabular}{|c|c|c|c|c|c|c|c|c|c|c|c|}
\hline \multicolumn{12}{|c|}{ Statistics } \\
\hline Variable & Gender & $\mathbf{N}$ & $\begin{array}{l}\text { Lower } \\
\text { CL Mean }\end{array}$ & Mean & $\begin{array}{c}\text { Upper } \\
\text { CL } \\
\text { Mean }\end{array}$ & $\begin{array}{c}\text { Lower } \\
\text { CL Std } \\
\text { Dev }\end{array}$ & Std Dev & $\begin{array}{c}\text { Upper } \\
\text { CL Std } \\
\text { Dev }\end{array}$ & $\begin{array}{l}\text { Std } \\
\text { Err }\end{array}$ & Minimum & Maximum \\
\hline Cost & Female & 73 & 28099 & 31004 & 33908 & 10707 & 12450 & 14876 & 1457.2 & 10500 & 69248 \\
\hline Cost & Male & 127 & 30293 & 32575 & 34856 & 11566 & 12991 & 14820 & 1152.8 & 8810 & 74150 \\
\hline Cost & Diff (1-2) & & -2194 & -1571 & -948 & -859 & -541 & 56 & 304.4 & & \\
\hline \multicolumn{12}{|c|}{ 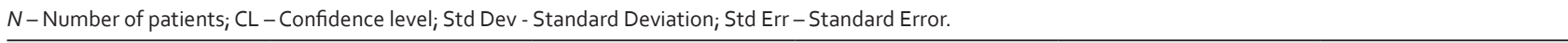 } \\
\hline \multicolumn{12}{|c|}{$T$-Tests } \\
\hline \multicolumn{2}{|c|}{ Variable } & \multicolumn{2}{|r|}{ Method } & \multicolumn{3}{|c|}{ Variances } & DF & \multicolumn{2}{|r|}{$t$ Value } & \multicolumn{2}{|r|}{$\operatorname{Pr}>|t|$} \\
\hline \multicolumn{2}{|c|}{ Cost } & \multicolumn{2}{|r|}{ Pooled } & \multicolumn{2}{|r|}{ Equal } & & 198 & \multicolumn{2}{|r|}{-0.84} & \multicolumn{2}{|r|}{0.4042} \\
\hline \multicolumn{2}{|c|}{ Cost } & \multicolumn{2}{|c|}{ Satterthwaite } & \multicolumn{2}{|r|}{ Unequal } & & 156 & \multicolumn{2}{|r|}{-0.85} & \multicolumn{2}{|r|}{0.3991} \\
\hline \multicolumn{12}{|c|}{ DF-Degree of Freedom; Pr-Probability. } \\
\hline \multicolumn{12}{|c|}{ Equality of Variances } \\
\hline \multicolumn{2}{|c|}{ Variable } & \multicolumn{2}{|r|}{ Method } & \multicolumn{3}{|c|}{ Num DF } & Den DF & \multicolumn{2}{|r|}{ F Value } & \multicolumn{2}{|r|}{$\operatorname{Pr}>\mathrm{F}$} \\
\hline \multicolumn{2}{|c|}{ Cost } & \multicolumn{2}{|r|}{ Folded F } & \multicolumn{2}{|r|}{126} & & 72 & \multicolumn{2}{|r|}{1.09} & \multicolumn{2}{|r|}{0.6999} \\
\hline
\end{tabular}

Num DF- Numerator of degrees of freedom; Den DF - Denominator of degree of freedom; Pr - Probabality.

\section{Table 8: Cost analysis based on culture report.}

Culture Report

Cost (Rs. $\pm S D)$

$\begin{array}{cc}\text { Positive } & \text { Rs. } 35,920 \pm 15,292 \\ \text { E. coli } & \text { Rs. } 24,767 \pm 15,498 \\ \text { Klebsiella } & \text { Rs. } 35,688 \pm 15,162 \\ \text { Negative } & \text { Rs. } 18,082 \pm 7,987\end{array}$

Table 9: Statistics based on blood culture report.

\section{Statistics}

\begin{tabular}{cccccccccccc}
\hline Variable & Culture & N & $\begin{array}{c}\text { Lower } \\
\text { CL } \\
\text { Mean }\end{array}$ & Mean & $\begin{array}{c}\text { Upper } \\
\text { CL } \\
\text { Mean }\end{array}$ & $\begin{array}{c}\text { Lower } \\
\text { CL Std } \\
\text { Dev }\end{array}$ & Std Dev & $\begin{array}{c}\text { Upper } \\
\text { CL Std } \\
\text { Dev }\end{array}$ & $\begin{array}{c}\text { Std } \\
\text { Err }\end{array}$ & Minimum & Maximum \\
\hline Cost & Negative & 100 & 26498 & 28082 & 29667 & 7012.8 & 7987.19 & 9278.5 & 798.72 & 8810.00 & 52653 \\
Cost & Positive & 100 & 32886 & 35920 & 38954 & 13427 & 15292.31 & 17765 & 1529.2 & 20200.00 & 74150 \\
Cost & Diff (1-2) & & -6388 & -7838 & -9287 & -6414.2 & -7305.12 & -8486.5 & -730.48 & \\
\hline
\end{tabular}

N-Number of patients; CL - Confidence level; Std Dev - Standard Deviation; Std Err - Standard Error.

\begin{tabular}{|c|c|c|c|c|c|}
\hline \multicolumn{6}{|c|}{$T$-Tests } \\
\hline Variable & Method & Variances & DF & $t$ Value & $\operatorname{Pr}>|t|$ \\
\hline Cost & Pooled & Equal & 198 & -4.54 & $<0.0001$ \\
\hline Cost & Satterthwaite & Unequal & 149 & -4.54 & $<0.0001$ \\
\hline
\end{tabular}

DF-Degree of Freedom; $\mathrm{Pr}$ - Probability.

\begin{tabular}{cccccc}
\hline & \multicolumn{4}{c}{ Equality of Variances } \\
\hline Variable & Method & Num DF & Den DF & F Value & \\
\hline Cost & Folded F & 99 & 99 & 3.67 & 0.0001 \\
\hline
\end{tabular}

Num DF- Numerator of degrees of freedom; Den DF - Denominator of degree of freedom. Pr - Probabality. 
Table 10: Statistics based on culture organisms.

\begin{tabular}{|c|c|c|c|c|c|c|c|c|c|c|c|}
\hline \multicolumn{12}{|c|}{ Statistics } \\
\hline Variable & Culture & $\mathbf{N}$ & $\begin{array}{c}\text { Lower } \\
\text { CL } \\
\text { Mean }\end{array}$ & Mean & $\begin{array}{l}\text { Upper CL } \\
\text { Mean }\end{array}$ & $\begin{array}{l}\text { Lower } \\
\text { CL Std } \\
\text { Dev }\end{array}$ & Std Dev & $\begin{array}{c}\text { Upper } \\
\text { CL Std } \\
\text { Dev }\end{array}$ & $\begin{array}{l}\text { Std } \\
\text { Err }\end{array}$ & Minimum & Maximum \\
\hline Cost & E. coli & 61 & 32099 & 36068 & 40038 & 13154 & 15498 & 18868 & 1984.4 & 21068 & 69800 \\
\hline Cost & Klebsiella & 39 & 30773 & 35688 & 40604 & 12392 & 15163 & 19541 & 2427.9 & 20200 & 74150 \\
\hline Cost & Diff (1-2) & & 1326 & 380 & -566 & 762 & 335 & -673 & -443.5 & & \\
\hline \multicolumn{12}{|c|}{$t$-Tests } \\
\hline \multicolumn{2}{|c|}{ Variable } & \multicolumn{3}{|c|}{ Method } & & \multicolumn{2}{|c|}{ Variances } & DF & \multicolumn{2}{|r|}{$t$ Value } & $\operatorname{Pr}>|t|$ \\
\hline \multicolumn{2}{|c|}{ Cost } & \multicolumn{3}{|c|}{ Pooled } & & \multicolumn{2}{|c|}{ Equal } & 98 & \multicolumn{2}{|r|}{0.12} & 0.9043 \\
\hline \multicolumn{2}{|c|}{ Cost } & \multicolumn{3}{|c|}{ Satterthwaite } & & \multicolumn{2}{|c|}{ Unequal } & 82.4 & \multicolumn{2}{|r|}{0.12} & 0.9039 \\
\hline
\end{tabular}

N- Number of patients; CL - Confidence level; Std Dev - Standard Deviation; Std Err - Standard Error. DF - Degree of Freedom; $\mathrm{Pr}-$ Probability.

\begin{tabular}{cccccc}
\hline & \multicolumn{4}{c}{ Equality of Variances } \\
\hline Variable & Method & Num DF & Den DF & Pr > F & F Value \\
\hline Cost & Folded F & 60 & 38 & 1.04 & 0.8994 \\
\hline
\end{tabular}

Num DF- Numerator of degrees of freedom; Den DF - Denominator of degree of freedom; Pr - Probabality,

\section{DISCUSSION}

In this survey of severe sepsis and septic shock among individuals who reside in the southern parts of India, several findings were noteworthy. Despite an overwhelming lack of resources, major time-sensitive metrics showed ability to approximate best practices employed in the USA and Europe., ${ }^{5,10,14}$ Of particular note, the median time from triage to antibiotics was 126 min and by $3 \mathrm{~h}$, nearly two thirds of the patients had received antibiotic therapy. We were unable to achieve $100 \%$ compliance with current recommendations that require the administration of empirical broad-spectrum antibiotics within $3 \mathrm{~h}$ of ED arrival; however, the compliance rate can be improved if enhanced surveillance of potential cases and systems-based approaches to improve sepsis care are implemented.

A total of 200 sepsis patients were enrolled in the study out of which 264 patients were documented. Out of them 100 patients were found blood culture positive and 100 patients were found blood culture negative. Majority of the patients were males $(63.5 \%)$ than females for both blood culture positive and negative sepsis. Similar study on "Prescribing pattern of antibiotics in pediatrics wards" done by Mestawot Feleke and his co investigators ${ }^{11}$ revealed that males are predominantly more than females.

The organisms isolated in this study were predominantly gram-negative bacilli (GNB) in both blood and urine cultures (54\% and $76 \%$, respectively). This contrasts the pattern of isolates in the USA, where gram-positive organisms standout as the predominant pathogens in severe sepsis and septic shock. ${ }^{15}$ This may reflect the relative frequency of a known or suspected urinary source of infection in our study cohort. A higher prevalence of gram negative sepsis has previously been reported at UHWI and this apparent propensity should be considered when empirical antibiotics are selected for patients with suspected sepsis. ${ }^{16}$ Among the 100 culture positive patients incidence of Escherichia coli was predominantly found in 61 patients $(61 \%)$ followed by Klebsiella pneumonia in 39 patients (39\%). This data is similar to the study done by Derek C. Angus and Tom van der Poll ${ }^{17}$ shows that $E$. coli is most common organism causing sepsis. As abnormal range of WBC is the major parameter involved in diagnosis of sepsis patients, the average WBC count were calculated for both culture positive and culture negative patients. The average WBC count for culture positive was 25,789 cells/ micro liter and for culture negative were 22,696 25,789 cells / micro liter where these findings were similar to the study on Antibiotic prescribing pattern in pediatrics in patients with $1^{\text {st }}$ time wheezing by Soumya Patra, et al. ${ }^{18}$

Patients enrolled were of different age groups, most of them were neonates $(64 \%)$ followed by adults and middle age (24\%), infants (20\%), geriatrics $(2 \%)$, children and adolescence $(1 \%)$. The data obtained was similar to the study done on "The appropriateness of prescribing antibiotics in the community in Europe" by Evelin ME van Bijnen, et al. ${ }^{19}$ Consistent with prior studies of severe sepsis, older individuals and neonates were over-represented in the study population., ${ }^{6,14,20-22}$ This agerelated prevalence has been attributed to a progressive immune dysfunction that accompanies ageing, where a failure of leukocytes to process antigens and an alteration in inflammatory cytokine expression ensue. ${ }^{23-28}$ The elderly are also more likely to contract diseases with a 
propensity to induce sepsis such as pneumonia or urinary tract infections. Among all the complaints observed in sepsis patients fever accounted for $42.5 \%$. This data is similar to the study findings of Ravika Kanish. ${ }^{29}$

Treatment pattern and total antibiotic usage for both culture positive and negative patients were analysed in the study and it was observed that both IV and Oral route of Piperacillin and Tazobactum (beta lactums) and Vancomycin (Glycopeptide) were prescribed more frequently compared to the other antibiotic class of drugs like Cefpodoxime (Cephalosporins), Clindamycin, Tobramycin, (Aminoglycoside) and Meropenem, Imipenem (Carbapenems). This is similar to the study findings by $\mathrm{H}$. N. Nagesh. ${ }^{30}$

In this study it was identified that the pattern of generic names prescribing was $76.3 \%$ which was considerably sufficient and brand names prescribing was $23.7 \%$. The similar data is observed in study by Mestawot Feleke. ${ }^{11}$ The percentage of these drugs prescribed by generic names should be ideally be $100 \%$. According to $\mathrm{WHO}$ recommendations, prescribing and dispensing of drugs by its generic name avoids confusion between prescribers and dispensers.

Cost of treatment in culture positive patients ranged from Rs.51,212 to 19,991 and the cost of treatment in culture negative patients ranged from Rs.26,069 to 10,095. The variation in the cost of treatment may be due to change in treatment location. The commonly prescribed antibiotics were Piperacillin + Tazobactum, Vancomycin, Clindamycin, Tobramycin, Cefpodoxime, Meropenem and Imipenam.

From the obtained data, the reoccurrence rate for Klebsiella $(42.2 \%)$ was more than E. coli $(35.1 \%)$ is accounted for and for culture negative patients' reoccurrence was found in $24 \%$ of the patients. Main factor which caused reoccurrence might be due to emergence of resistance strains and treatment failure due to irrational use of antibiotics with respect to dose, frequency and duration of antibiotics administration. This study recommends that selection of antibiotic should be based on culture and sensitivity test.

The pharmacoeconomic aspects of the patients cost of treatment in culture positive patients ranged from Rs. 19,991 to 51,212 (the cost for patients with presence of Klebsiella ranged from Rs. 20,526 to 50,850 and the cost for patients with presence of $E$. coli ranged from Rs. 9,269 to 40,265) and the cost of treatment in culture negative patients ranged from Rs. 10,095 to 26,069 . Culture positive patients require more doses of antibiotic and more number of hospital stays which increased money burden.

Cost analysis based on the hospital stay for all the sepsis patients showed that average cost for $0-5$ days were found to be Rs. 15,602, for $6-10$ days Rs. 28,275, for $11-15$ days Rs. 42,960, for $16-20$ days Rs. 50,699. The cost is significantly high in patients with hospital stay for $16-20$ days i.e. Rs. 50,699 and less cost for $0-5$ days i.e. Rs. 15,602. These results were in coherence with the study on by Ronald EP Frenkel, Max Frenkel et al. ${ }^{31}$

\section{Limitations}

This study is limited by the fact that we relied on small sample size that may compromise the generalizability of the findings.

The other limitation of the present study is that findings were from different study sites so that it was difficult to address every point that need to be addressed.

The data of LAMA (Leave against medical advice) patients were not available. Therefore, cost to benefit ratio of patients could not be analyzed.

\section{CONCLUSION}

Majority of the patients were affected by E. coli organism and Klebsiella organism. Piperacillin + Tazobactum, Vancomycin, Cefpodoxime, Tobramycin, Clindamycin, Meropenam, Imipenam and the other class of drugs like Paracetamol, Pantaprazole, Dopamine, Tramadol and Multivitamin were commonly prescribed drugs. Improvements in outcome, however, may be achievable with implementation of EGDT and SSC principles and based on our results, further exploration of such a possibility is warranted.

\section{ACKNOWLEDGEMENT}

We would like to express our sincere thanks to Dr. G. Ramesh, Pediatrician at Amrutha Children's Hospital, Dr. V. Ravinder, General Physician at Max Care Hospital for their support and guidance and to all the Doctors in Rohini Multispeciality Hospital, who helped us in making the project success by providing adequate facilities to carry out the project work.

We should be failing in our duties if we don't mention the help of Authors of journals and books, the pillars of our research work. Finally, but immensely, we thank all the patients who participated in the study without whom the study would not been possible.

Indian Journal of Pharmacy Practice, Vol 12, Issue 2, Apr-Jun, 2019 


\section{CONFLICT OF INTEREST}

The authors declare no conflict of interest.

\section{ABBREVIATIONS}

AHRQ: Agency for Healthcare Research and Quality; ED: Emergency Department; EGDT: Early Goal Directed Therapy; HR: Heart Rate; ICU: Intensive Care Unit; LAMA: Leave against medical advice; LOS: Length of Stay; RR: Respiratory Rate; SIRS: Systemic Inflammatory Response Syndrome; SSC: Surviving Sepsis Campaign; WBC: White Blood Cell.

\section{SUMMARY}

The research summaries that the blood culture test is to be performed before prescribing the antibiotic therapy to the patients and the cost of the sepsis patients depends on the hospital stay, type of culture and antibiotics given.

\section{REFERENCES}

1. Anthony F, Eugene B, Dennis K, Stephen H, Dan LL, Larry JJ, et al. Harrison's Principles of Internal Medicine $17^{\text {th }}$ edition. New York: McGraw-Hill Companies. 2008;2.

2. Lee G, Andrew I, Schafer RJA. Goldman's Cecil Medicine. $25^{\text {th }}$ edition. Netherlands: Elsevier B.V. 2011.

3. DenHoogen AV, Leo JG, Verboon-Maciolek MA, Andre F, Tannette GK. Longterm trends in the epidemiology of neonatal sepsis and antibiotic susceptibility of causative agents. Neonatology. 2009;97(1):22-8.

4. Dellinger RP. Cardiovascular management of septic shock. Crit Care Med. 2003;31(3):946-55.

5. Osborn TM, Tracy JK, Dunne JR, Pasquale M, Napolitano LM. Epidemiology of sepsis in patients with traumatic injury. Crit Care Med. 2004;32(11):2234-40.

6. Angus DC, Linde-Zwirble WT, Lidicker J, Clermont G, Carcillo J, Pinsky MR. Epidemiology of severe sepsis in the United States: Analysis of incidence, outcome and associated costs of care. Crit Care Med. 2001;29(7):1303-10.

7. Watson RS, Carcillo JA, Linde-Zwirble WT, Clermont G, Lidicker J, Angus DC. The epidemiology of severe sepsis in children in the United States. Am J Respir Crit Care Med. 2003;167(5):695-701.

8. Brun-Buisson C, Meshaka P, Pinton P, Vallet B. EPISEPSIS Study Group. EPISEPSIS: Are appraisal of the epidemiology and outcome of severe sepsis in French intensive care units. Intensive Care Med. 2004;30(4):580-8.

9. Finfer S, Bellomo R, Lipman J, French C, Dobb G, Myburgh J. Adult population incidence of severe sepsis in Australian and New Zealand intensive care units. Intensive Care Med. 2004;30(4):589-96.

10. Nguyen HB, Rivers EP, Abrahamian FM. Severe sepsis and septic shock: review of the literature and emergency department management guidelines. Ann Emerg Med. 2006;48(1):28-54.
11. Mestawot F, Wubante $Y$, Jimma LL. Prescribing pattern of antibiotics in pediatric wards. Department of Pharmacy. 2013;2(6):718-22.

12. Wang HE, Shapiro NI, Angus DC, et al. National estimates of severe sepsis in United States emergency departments. Crit Care Med. 2007;35(8):1928-36. [PubMed: 17581480]

13. Blow O, Magliore L, Claridge JA, Butler K, Young JS. The golden h and the silver day: Detection and correction of occult hypoperfusion within $24 \mathrm{~h}$ improves out come from major trauma. J Trauma. 1999;47(5):964-9.

14. Rivers EP, Nguyen HB, Havstad S. Early goal-directed therapy in the treatment of severe sepsis and septic shock. N Engl J Med. 2001;345(19):1368-77.

15. Martin GS, Mannino DM, Eaton S. The epidemiology of sepsis in the United States from 1979 through 2000. N Engl J Med. 2003;348(16):1546-54.

16. Edwards R, Hutson R, Johnson J, Sherwin R, Gordon-Strachan G, Frankson $\mathrm{M}$, et al. Severe sepsis in the emergency department: an observational cohort study from the university hospital of the West Indies. West Indian Med J. 2013;62(3):224-9.

17. Angus DC, Linde-Zwirble WT, Gilles C, Daniel EB, Bruce RB, Wesley EE, et al. Cost-effectiveness of drotrecogin alfa (activated) in the treatment of severe sepsis. Department of Critical Care Medicine. 2003;31(1):1-11.

18. Soumya P, Varinder S, Harish KP, Jagdish C. Antibiotic prescribing pattern in paediatric in patients with first time wheezing. Department of Paediatrics. 2011;37(1):1-5.

19. Bijnen EMEV, DenCasper DJH, John PW, Ellen ES, Robert AV, Cathrien AB, et al. The appropriateness of prescribing antibiotics in the community in Europe. Department of Medicine. 2011;293(11):1-5.

20. Martin G, Mannino D, Moss M. The effect of age on the development and outcome of adult sepsis. Crit Care Med. 2006;34(1):15-21.

21. Brun-Buisson C, Doyon F, Carlet J. Bacteremia and severe sepsis in adults: a multicenter prospective survey in ICUs and wards of 24 hospitals. French Bacteremia-Sepsis Study Group. Am J Respir Crit Care Med. 1996;154(3):617-24.

22. Baine WB, Yu W, Summe JP. The epidemiology of hospitalization of elderly Americans for septicemia or bacteremia in 1991-1998: Application of Medicare claims data. Ann Epidemiol. 2001;11(2):118-26.

23. Turnbull IR, Wlzorek JJ, Osborne D. Effects of age on mortality and antibiotic efficacy in cecal ligation and puncture. Shock. 2003;19(4):310-13.

24. Pawelec G, Solana R, Remarque E. Impact of ageing on innate immunity. J Leukoc Biol. 1998;64(6):703-12.

25. Tateda K, Matsumoto T, Miyazaki S. Lipopolysaccharide-induced lethality and cytokine production in aged mice. Infect Immun. 1996;64(3):769-74.

26. Bruunsgaard H, Skinhoj P, Qvist J. Elderly humans show prolonged in vivo inflammatory activity during pneumococcal infections. J Infect Dis. 1999;180(2):551-4.

27. Gabriel P, Cakman I, Rink L. Overproduction of monokines by leukocytes after stimulation with lipopolysaccharide in the elderly. Exp Gerontol. 2002;37(23):235-47.

28. Yamamoto K, Shimokawa T, Yi H. Ageing accelerates endotoxin induced thrombosis: increased responses of plasminogen activator inhibitor-1 and lipopolysaccharide signaling with ageing. Am J Pathol. 2002;161(5):1805-14.

29. Ravika K, Kanchan G, Shivani J, Bains HS, Sandeep K. Prescribing pattern of antibiotics in the department of pediatrics in tertiary care medical college hospital in Northern India. Department of Paediatrics. 2014;5(4):69-72.

30. Nagesh HN, Basavanna PL, Savitha MR. Antibiotic usage and auditing of antibiotic sensitivity pattern of culture positive neonatal septicemia in neonatal intensive care unit of a tertiary care hospital: A retrospective study. International Journal of Contemporary Pediatrics. 2014;1(3):142-7.

31. Ronald EPF, Frenkel M, Allison T. Pharmacoeconomic analysis of prostaglandin and prostamide therapy for patients with Glucoma or Occular Hypertension. BMC Ophthalmology. 2007;7(1):16. 